\title{
Secondary Reformer Refractory Dry Out Operation
}

\author{
Prem Baboo \\ DGM (Production \& Process)
}

\begin{abstract}
Secondary reformer refractory baking and dry out cycle requires very slow and controlled heating of refractory. Thermal stresses will be produced if heating rate is too rapid. Longer period of low temperature drying causes more even heat distribution resulting better refractory dry out. It is very much important that proper dry out of secondary reformer refractories as water is the common solvent for mixing refractory material. This article covers problems faced during drying out operation is described present information to better explain when there is a need for a refractory dryout and the critical aspects. The changes in temperature can have catastrophic effects on refractory systems. This has sometimes led to refractory failure before reaching normal operating conditions or premature deterioration of lining systems leading to unexpected, time consuming repairs required before or during scheduled outages. One cannot fault a calculated risk to get a unit back into production, but many times these decisions are made by those not even aware they are exposing a piece of equipment to any abnormal risk.It is therefore imperative that all parties work closely together to ensure a proper dryout, which ultimately maximizes the performance of the refractory lining in the application for which it was designed.
\end{abstract}

Keyword: -Refractory, Drying out, burner, CNG. Secondary Reformer.

\section{INTRODUCTION}

Dangote Fertilizer Project consists in the realization of an Ammonia and Urea complex with associated facilities. The
Project under progress at LEKKI Free Zone in Ibeiju-Lekki Local Government Area of Lagos State, Nigeria. The Dangote group is a Nigerian multinational industrial conglomerate, founded by Aliko Dangote. It is the Largest Conglomerate in the West Africa and one of the largest in the African Continent.Ammonia and Urea complex includes:

2x2200 MTPD Ammonia Trains based on HTAS technology (and BASF technology for $\mathrm{CO}_{2}$ capture in Ammonia Plants). $2 \times 3850$ MTPD Melt Urea Trains based on Saipem Technology.

2x3850 MTPD Urea Granulation Trains based on Udhe Fertilizer technology. Associated Utility Units.

Commissioning activities under progress in train-1 plant in which Ammonia Train-1 \& 2 Secondary reformer drying out operation has been successfully completed. However problem faced in drying out operation in train -1 successfully rectified in Train-2.

\section{AMMONIA PLANT BRIEF DESCRIPTION}

In ammonia Plant ammonia is produced from synthesis gas containing hydrogen and nitrogen in the ratio of approximately $3: 1$.Besides these components, the synthesis gas also contains inert gases such as argon and methane to a limited extent. The source of $\mathrm{H}_{2}$ is demineralized water (steam) and the hydrocarbons in the natural gas. The source of $\mathrm{N}_{2}$ is the atmospheric air. The source of $\mathrm{CO}_{2}$ is the hydrocarbons in the natural gas feed. Product ammonia and $\mathrm{CO}_{2}$ is sending to urea plant. The main function of the plant is illustrated in the figure-1

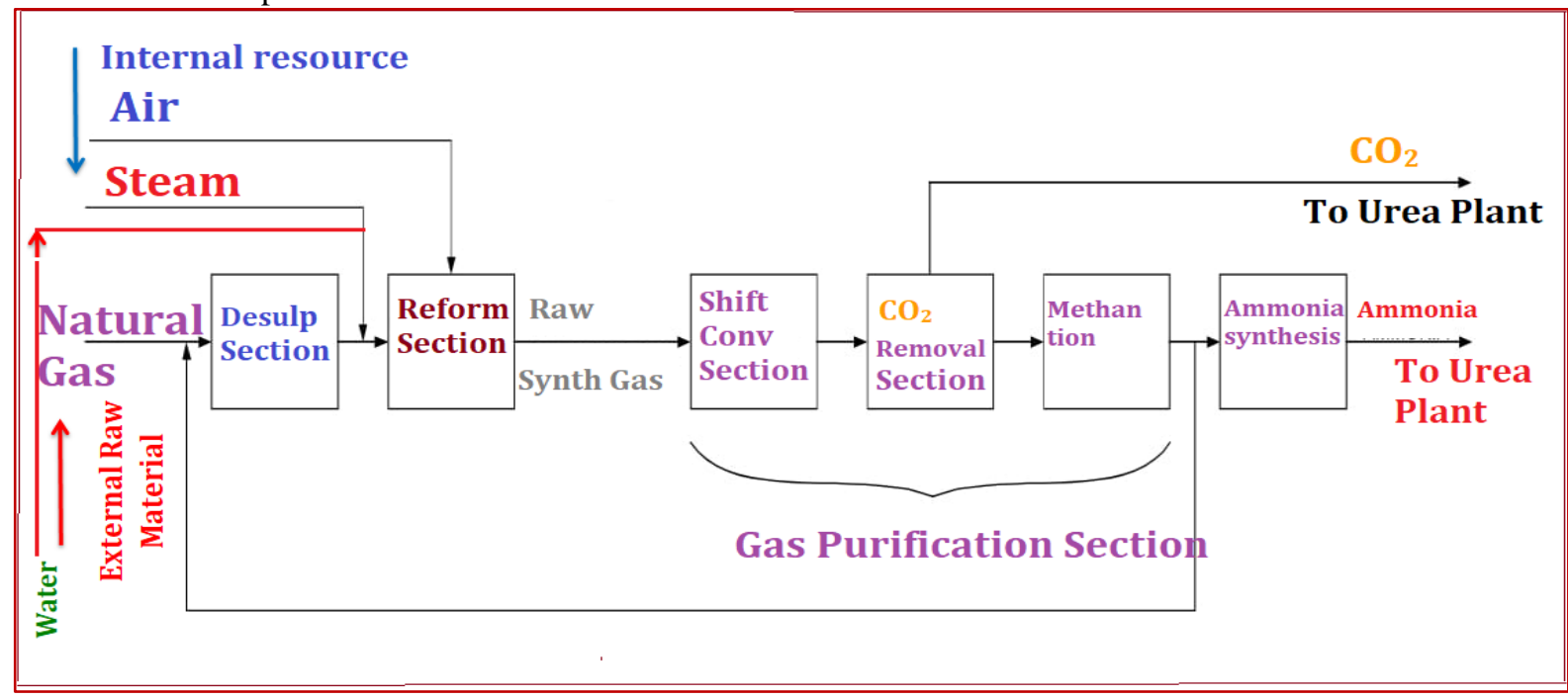

Fig-1(Brief Flow diagram of Ammonia plant) 
The hydrocarbon feed is desulphurized to the ppb level in the desulphurization section. The desulphurized hydrocarbon feed is reformed with steam and air into raw synthesis gas (process gas). The gas contains mainly hydrogen, Nitrogen, Carbon monoxide, Carbon dioxide and steam. In the gas purification section, the $\mathrm{CO}$ is first converted into $\mathrm{CO}_{2}$. Then the $\mathrm{CO}_{2}$ is removed from the process gas in the $\mathrm{CO}_{2}$ removal section. The $\mathrm{CO}$ and $\mathrm{CO}_{2}$ residues in the gas outlet of the $\mathrm{CO}_{2}$ removal unit are converted into methane by reaction with $\mathrm{H}_{2}$ (methanation) before the synthesis gas is sent to the ammonia synthesis loop. The purified synthesis gas is compressed and then routed to the ammonia synthesis loop, where it is converted into ammonia. In order to limit the accumulation of argon and methane in the loop, a purge stream is taken. The liquid ammonia product is depressurised during which the dissolved gases, let-down gas and inert gas, are flashed off.

\section{REFORMER BRIEF DECRIPTION}

The gas from the Primary reformer is passed on to the Secondary reformer, 11-R-203, through a refractory lined transfer line. The gas is admitted to the vessel through a top dome mixing chamber, where it is mixed with the process air which has been compressed to $39 \mathrm{~kg} / \mathrm{cm}^{2} \mathrm{~g}$ by the Process air compressor, $11-\mathrm{K}-421$, and preheated to $550^{\circ} \mathrm{C}$ in the flue gas heat recovery section. The Secondary reformer is a refractory lined vessel. The burner mixer is mounted at the top of the vessel. Partial combustion takes place in the top of 11-R-203 and causes a considerable increase in the temperature. From the combustion zone, the gas passes down through a catalyst bed, where the last part of the reforming takes place as the gas cools. The temperature of the process gas leaving the Secondary reformer is about $1000^{\circ} \mathrm{C}$, and the methane concentration is 0.40 mole\% (dry).The Secondary reformer outlet gas contains about 14.34 mole $\% \mathrm{CO}$ and 7.4 mole $\% \mathrm{CO}_{2}$, so there is a theoretical risk of carbon formation according to the following Boudouard reaction:

\section{$2 \mathrm{CO} \Leftrightarrow \mathrm{CO}_{2}+\mathrm{C}$ (as soot)}

The lower limit for the reaction is $650^{\circ} \mathrm{C}$, since the reaction rate becomes too slow at lower temperatures. During cooling of the secondary reformer outlet gas to the inlet temperature for the HT CO-converter, the gas passes the temperature window, where the above reaction can occur. Cooling of the process gas takes place in the Waste heat boiler No.1, 11-E-208.The Secondary reformer is to be charged with the following Topsoe catalysts: a top layer of RKS-2, a main layer of RKS-2-7H. The catalyst bed rests on two layers of alumina balls with different sizes, and alumina tiles are placed on top of the catalyst bed to hold down the catalyst and to protect the catalyst from direct flame contact. Combustion of the process gas with air produces a gas temperature of $1100-1200^{\circ} \mathrm{C}$ in the upper section of the Secondary reformer.as shown in the figure- 2 . Because the reforming reaction of methane absorbs heat, the temperature decreases down through the catalyst. The catalyst begins to sinter in the temperature range of 1400$1500^{\circ} \mathrm{C}$.The activated catalyst must never be exposed to pure air at temperatures above $100^{\circ} \mathrm{C}$, this will cause spontaneous heating. As the oxidation heat cannot dissipate from the Secondary reformer, it could lead to overheating and destruction of the catalyst.

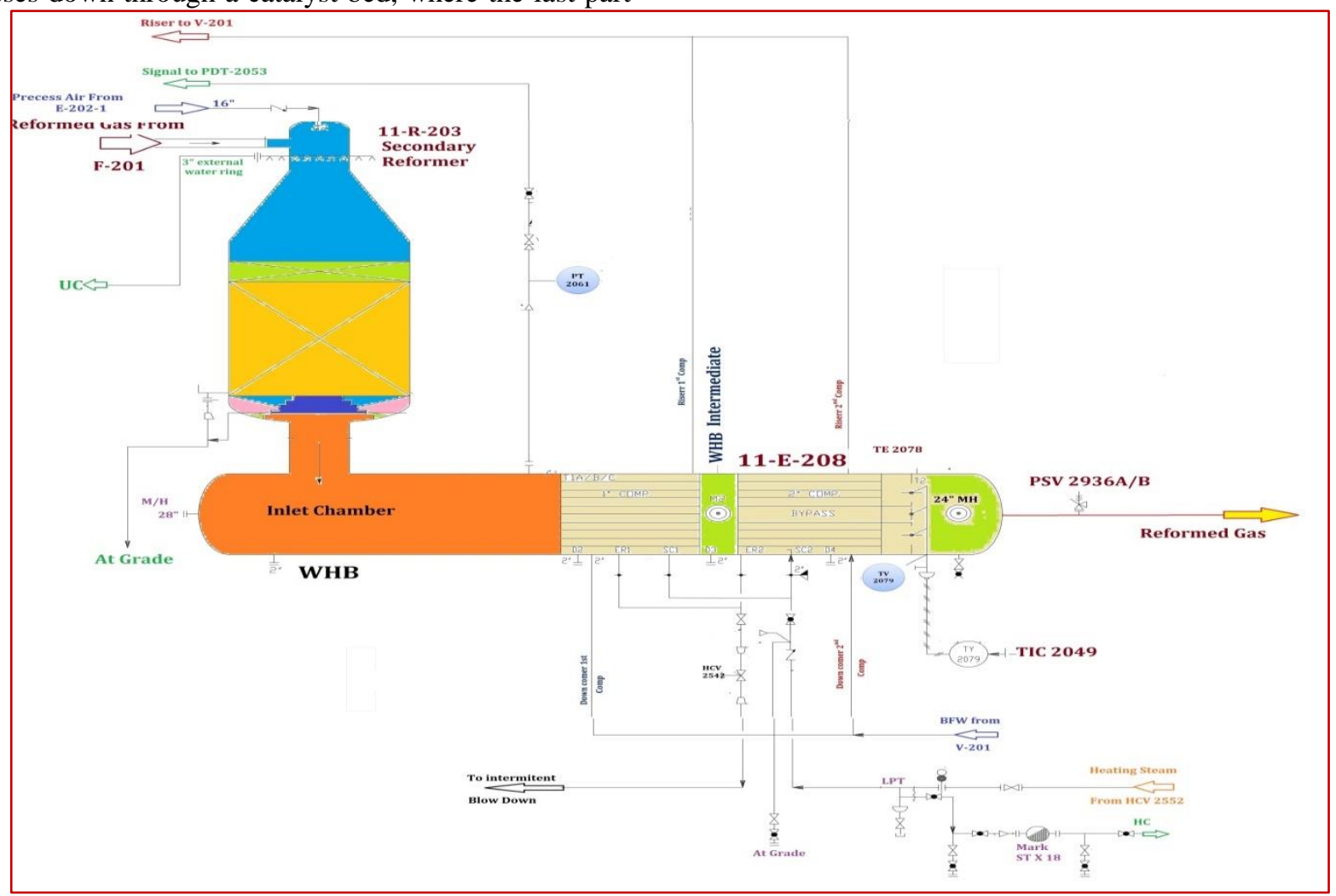

Fig-2(Secondary Reformer and waste heat boiler) 
The balance between reforming done in the Primary and Secondary reformers depends on preheat temperatures and the methane leakage. In practice the firing in the Primary reformer is adjusted so that the desired outlet conditions from the Secondary reformer are obtained with the amount of process air required to give a hydrogen/nitrogen ratio of approx. 3 to 1 in the synthesis gas to the loop. The high temperatures in the Primary and especially in the Secondary reformer necessitate chemical resistivity of the catalysts and of the Secondary reformer lining. HTAS particularly emphasize the use of catalysts free from silica and alkali, and lining with a very low content of silica, as volatile compounds otherwise will be carried out of the unit and deposited on the Waste heat boiler surfaces. The process gas leaves the reforming section at about $1000^{\circ} \mathrm{C}$. It is cooled to about $360^{\circ} \mathrm{C}$ in the Waste heat boiler, 11-E-208, where 120 $\mathrm{kg} / \mathrm{cm}^{2} \mathrm{~g}$ saturated steam is produced. After cooling, the gas flows to the HT CO-converter, 11-R-204.

\section{DRY OUT OPERION DESCRIPTION}

The most critical factor that can affect the cast refractory lining's lifespan is the refractory dry-out. This is the last stage in the installation process, and carries over into the start of operation and production during the commissioning phase. The objective of the carry-over is to bring the refractory lining to a condition suitable to commence operation. It is not possible to recommend a standard dry-out schedule to meet all conditions. Due to the variability of the products, their water contents, and their final desired properties it is crucial that the dry-out procedure, also known as the heat-up schedule, is obtained from the refractory manufacturer for that particular material and that it is followed strictly. The engineering and operation of any refractory drying out is a complex discipline that requires a detailed knowledge of the operation, together with a knowledge of the available source materials and their reliabilities such that temperature monitoring, controlling of the temperature available $\mathrm{LPG} / \mathrm{CNG}$ etc. Although the environment on site may make it difficult to achieve ideal operational conditions, steps can be taken to counteract the detrimental effects. Curing times and temperatures are also important to the cast lining life. It is important to allow for a 12-24 hour curing time to allow for the full hydration of the calcium aluminate binder. Loss of water from the surface of the cast before the cement is fully hydrated results in a weaker cast. If the material dries out before the cement has had time to fully hydrate, the castable strength will be reduced significantly. Dry out is the initial heating of castable lining in order to remove retained water from within the refractory castable without adversely affecting its structure or physical properties. The secondary reformer having monolithic refractory material contain water or water based liquid which are needed to place the material and help the setting process. Some of the water is chemically bonded in the crystal structure of the binder and some of the water is free water that was used a placement aid. All monolithic refractory binder system is similar in this regards. They are only different regarding the total amount of water. The quantity of free versus chemically bonded and a potential solid content that was dissolved in the liquid.

\section{PREPARATION OF DRY OUT SECONDARY REFORMER \& WASTE HEAT BOLER INLET CHAMBER}

First prepared the 9' brick wall with mortar between inlet chamber and intermediate chamber and applied two layers of $25 \mathrm{~mm}$ thick ceramic fibre blanket mineral wool on the outer surface of the shell as shown in the figure-3

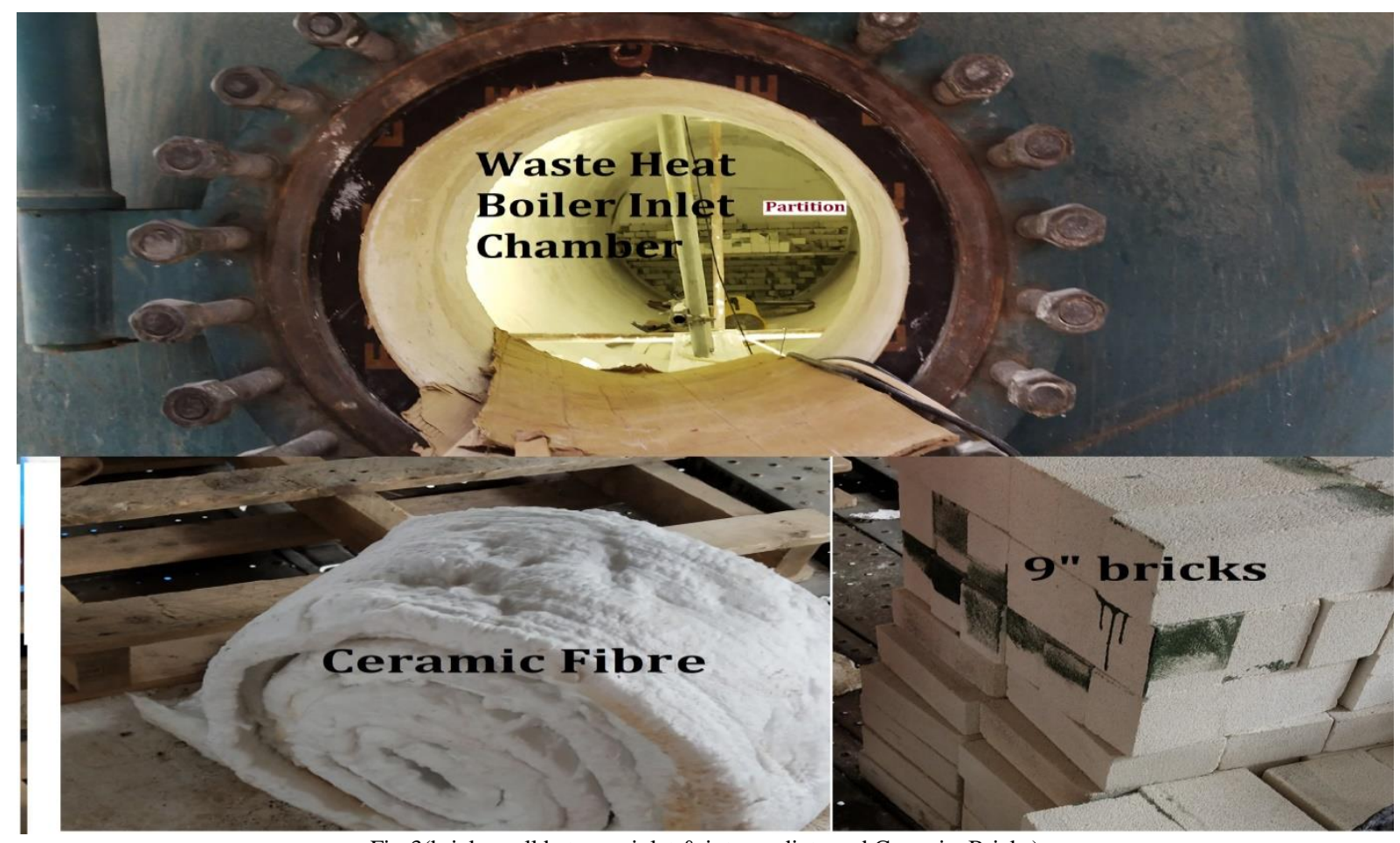

Fig-3(bricks wall between inlet \& intermediate and Ceramic, Bricks) 
The inlet chamber and intermediate chamber dry out carried out one by one first inlet chamber then intermediate chamber. Sealing of individual tube done in this way so that ceramic fibre can be removed easily. Damper arrangement was provided on top of the secondary reformer to control the flue gas vent to proper control of the temperature and positive pressure. A canopy also provided to protect the rain water ingress inside.

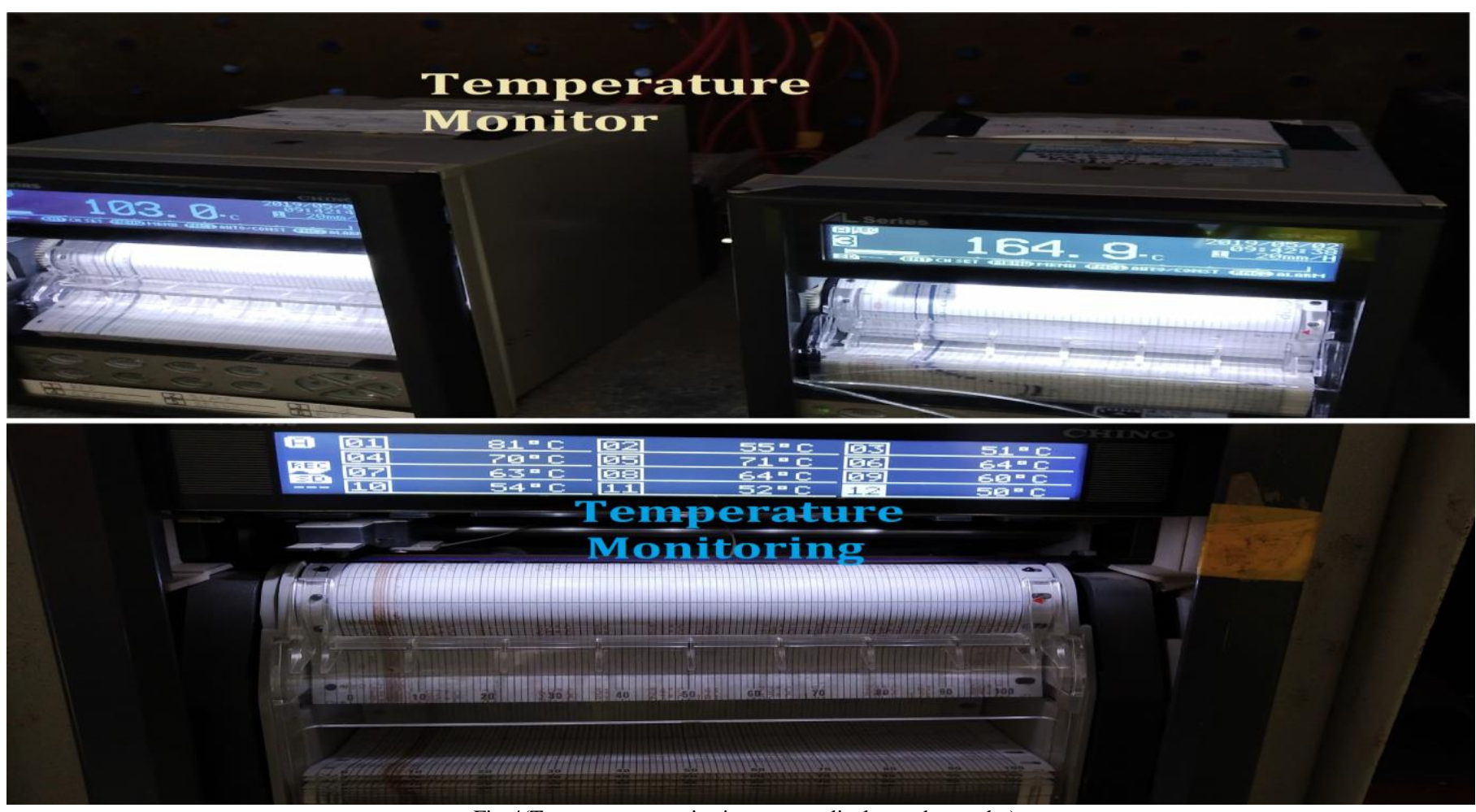

Fig-4(Temperature monitoring system display and recorder)

Installed the all thermocouple and temperature monitoring system (Figure-4) and inner thermocouple placed to air heater (for temperature monitoring of inlet hot fumes) and closed to outlet stack for monitoring of outlet hot fumes. In between inlet outlet some thermocouple are also installed as shown in the figure-5.Some thermocouple was also placed at various location on the outside of the shell. They were basically to check that the shell overheating (The maximum allowable shell temperature is $160^{\circ} \mathrm{C}$ )

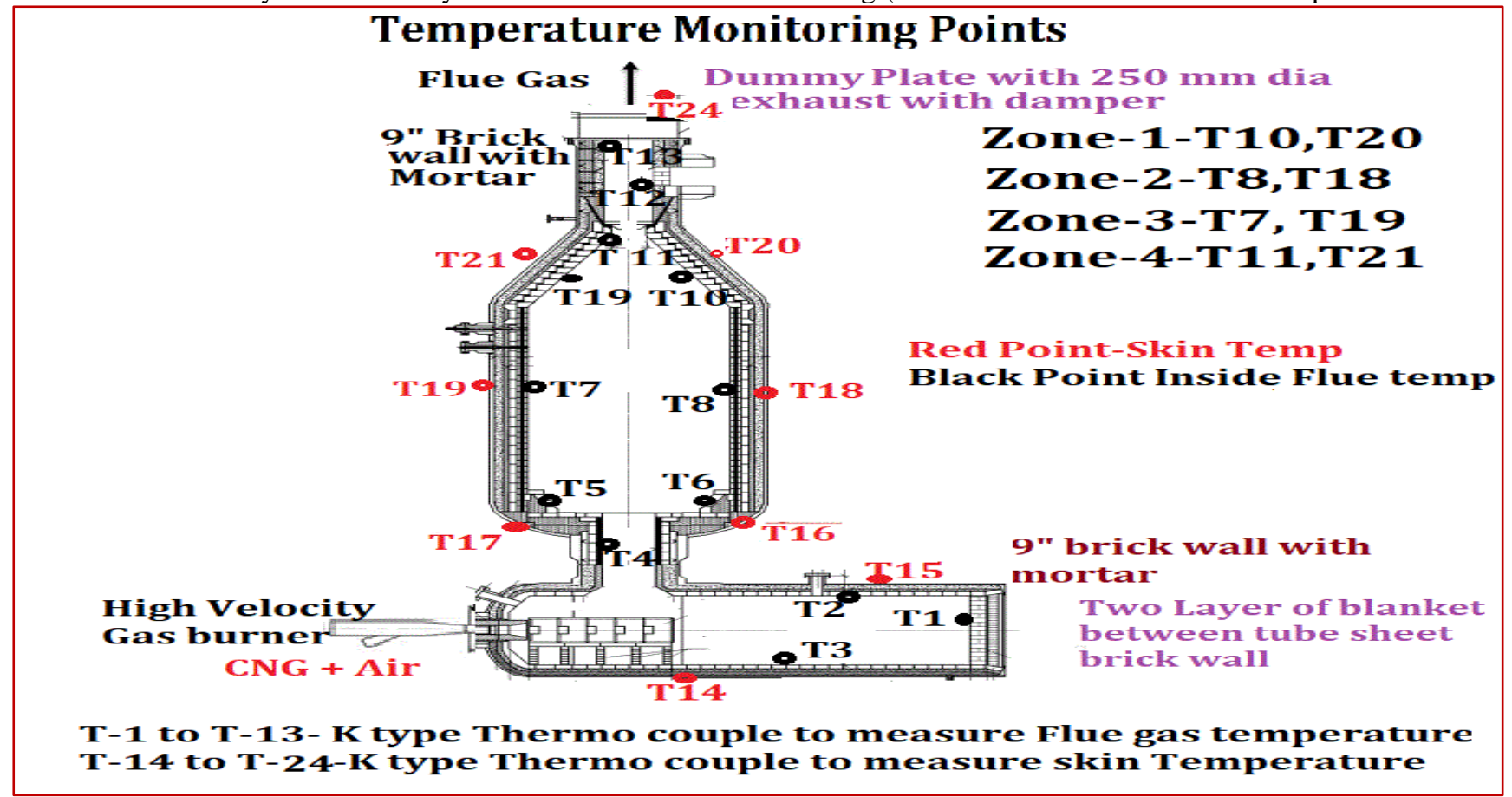

Fig-5(Detail Thermocouple location) 
The air heater was installed with high velocity burner. All nozzles man holes opening etc. sealed with line blind flanges, as shown in the figure-6. The dryout operation undertaken by the introduction of a hot air flow from high velocity gas burner. The burner was operated by CNG and had maximum released of $2.25 \mathrm{G} . \mathrm{Cal} / \mathrm{hr}$ and maximum combustion air flow was $5600 \mathrm{Nm}^{3} / \mathrm{hr}$ for refractory dry out of waste heat boiler with secondary reformer. The highest possible air flow maintained throughout the temperature cycle. For refractor dry out of waste heat boiler with secondary reformer burner deployed through manhole of the waste heat boiler as shown in the figure-6.The burner was operated with minimum flame length, such that only hot combustion products entered the assemblies subject to dryout. The combined forced convective and radiation heat transferred to the refractory inside face therefore ensured the highest degree of temperature uniformity. The turbulence within the assemblies created by HV gases had a scrubbing action on the refractory surfaced that also promoted rapid removal of moisture. Provision made at exhaust gas position to control the internal positive pressure and so promoted temperature uniformity.

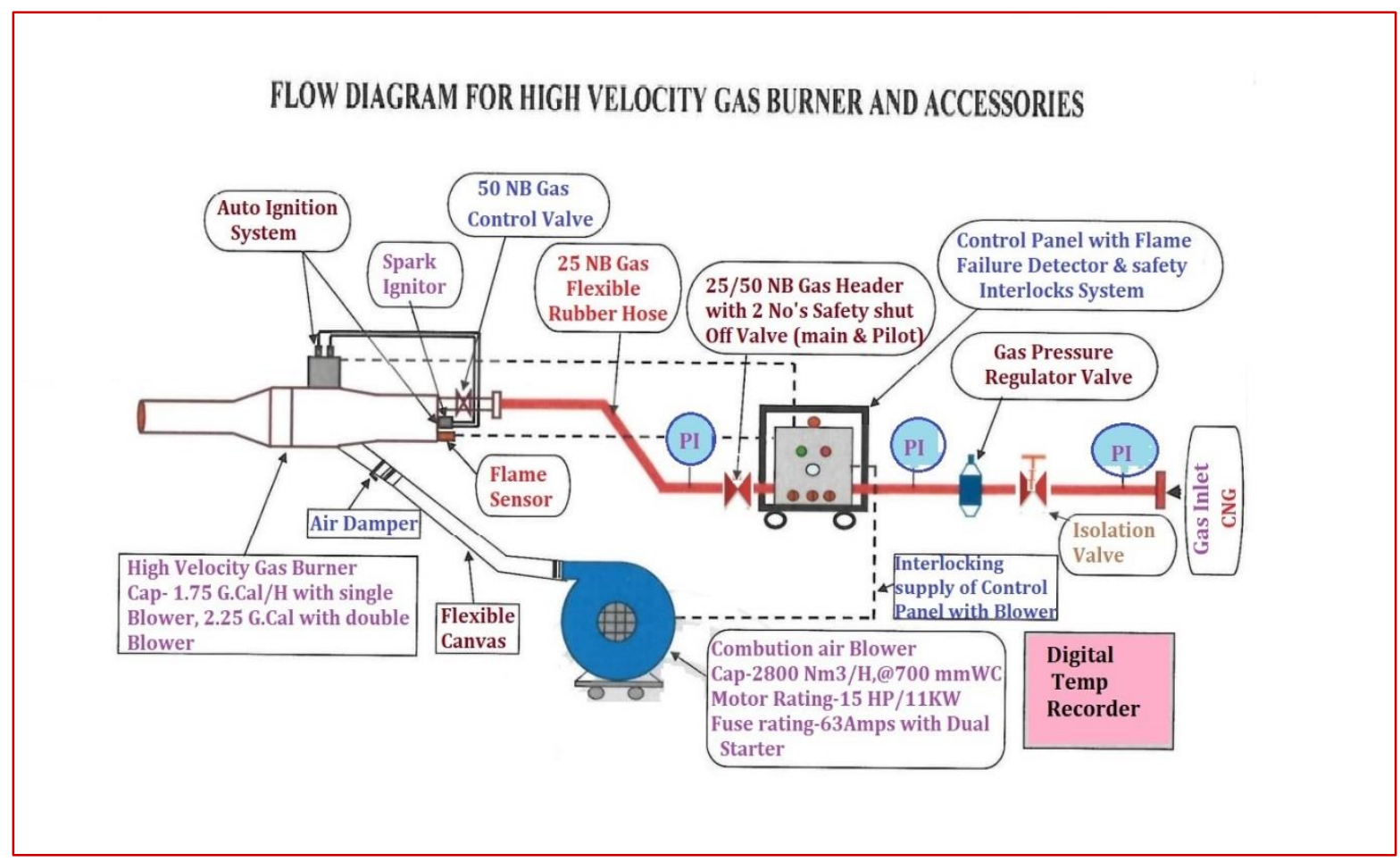

Fig-6(detail of burner digital monitoring, CNG location etc.)

In order to achieved this control a sliding flap damper plate provided at exhaust stack position as shown in the figure-7 (a) which could manually adjusted and locked provision. The two number air blower capacities were $2800 \mathrm{Nm} / \mathrm{hr}$ with static pressure $700 \mathrm{~mm}$ WC.

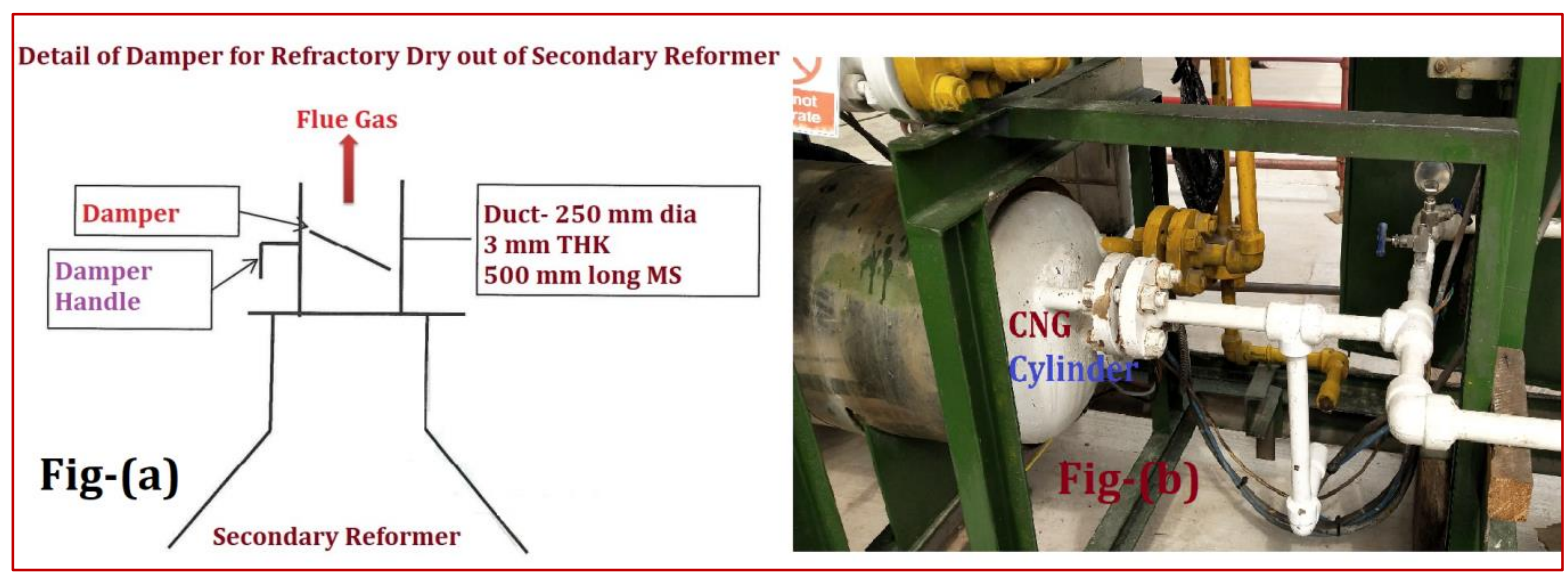

Fig-7(Top damper ad CNG controlling regulator) 
The burner fitted with intermittent spark ignition and flame monitored continuously by a U-V flame failure device with interlock to safety shut off valves so that the event of flame failure and fuel supply shut off and burner made safe. The installation of CNG storage tank distribution pipe work system and isolation valves complied with national and local regulations as shown in the figure- 7 (b)

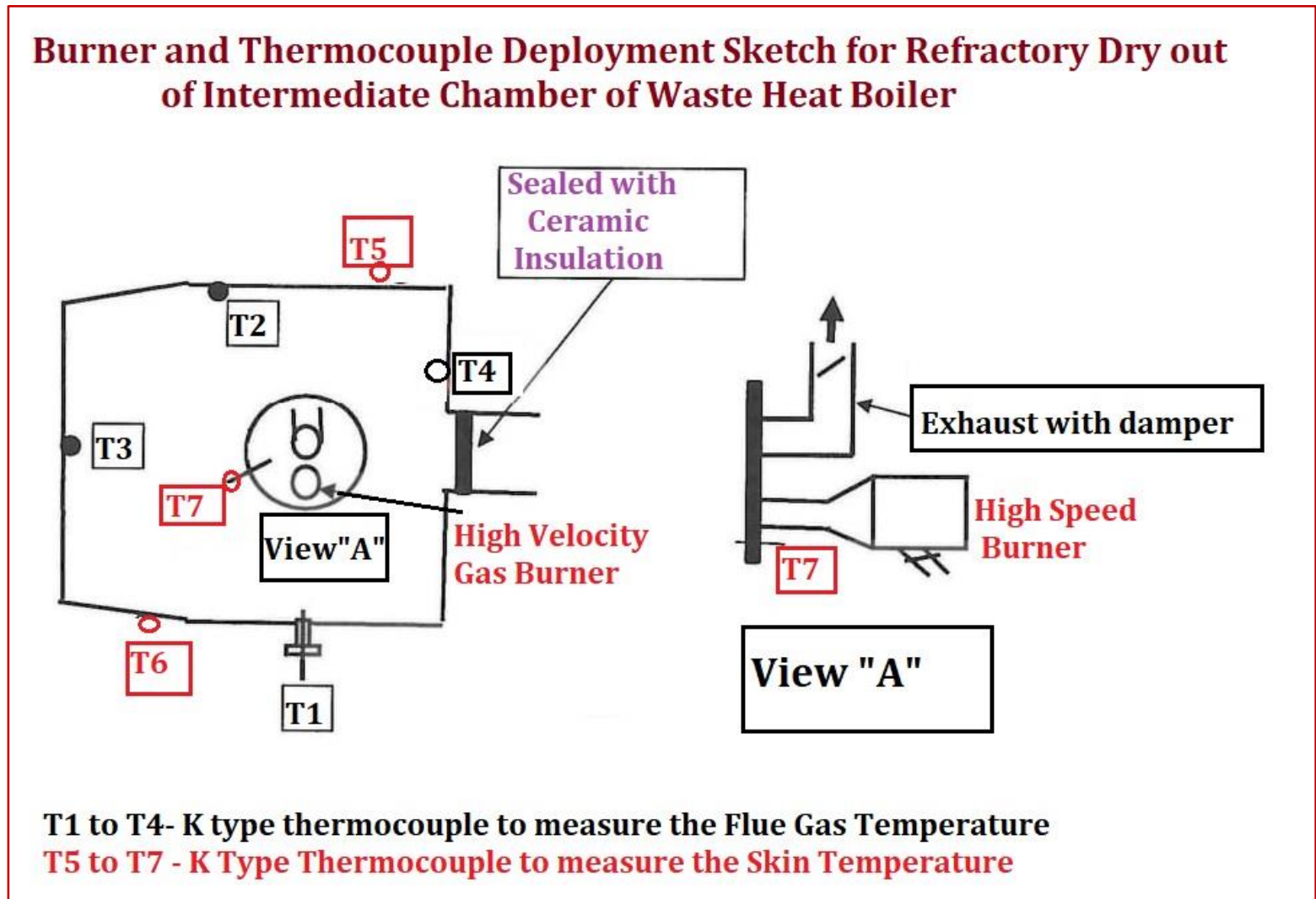

Fig-8(WHB intermediate burner location and damper exhaust)

The high velocity gas burner was controlled by manually adjustment of the fuel (CNG) isolation valve directly as shown in the figure-7(b). The combustion air was maintained maximum flow in so far as possible and required for pressurization of the assembly to unit. Consistent with stable burner operation control was affected by adjustment of the fuel. Flow rate was according as temperature trends indicated on the calibrated temperature recording instruments as shown in the figure-5. Calibrated K type thermocouples were fitted $15 \mathrm{~mm}$ above the refractory surface. The exhaust was also controlled temperature. Exhaust damper was operated by our experienced personal to maintain the positive pressure.

All the thermocouple was used made of $\mathrm{Ni}-\mathrm{Cr}$ conductor wire. The thermocouple were located as per shown in the figure-5.

All internal thermocouples were fitted for the purpose of measuring of the temperature of the gas stream attached to the surfaced of the refractory using fireclay. The thermocouple hot junction was protrude into the gas stream. All the thermocouple was calibrated. The recorders were potentiometric instruments self-compensating for ambient temperature.

All the internal thermocouples were fitted at the refractory surface achieved the minimum specified temperature for the prescribed period of time and not less. A hard log sheet was maintained for site activities and soft was also available. Before the burner lighting $24 \mathrm{hrs}$ air was blown it was important to monitor the flue gas when burner was used to carry out the drying. Normally the waste heat boiler tubes cooled to maintain them under the designed temperature. Even though every precaution was taken to prevent hot gases entering the boiler tubes also the temperature of the tubes at the sheet was monitored during the full time of dry out. The temperature was not increased beyond the rate mentioned in the scheduled graph as shown in the figure- 9 


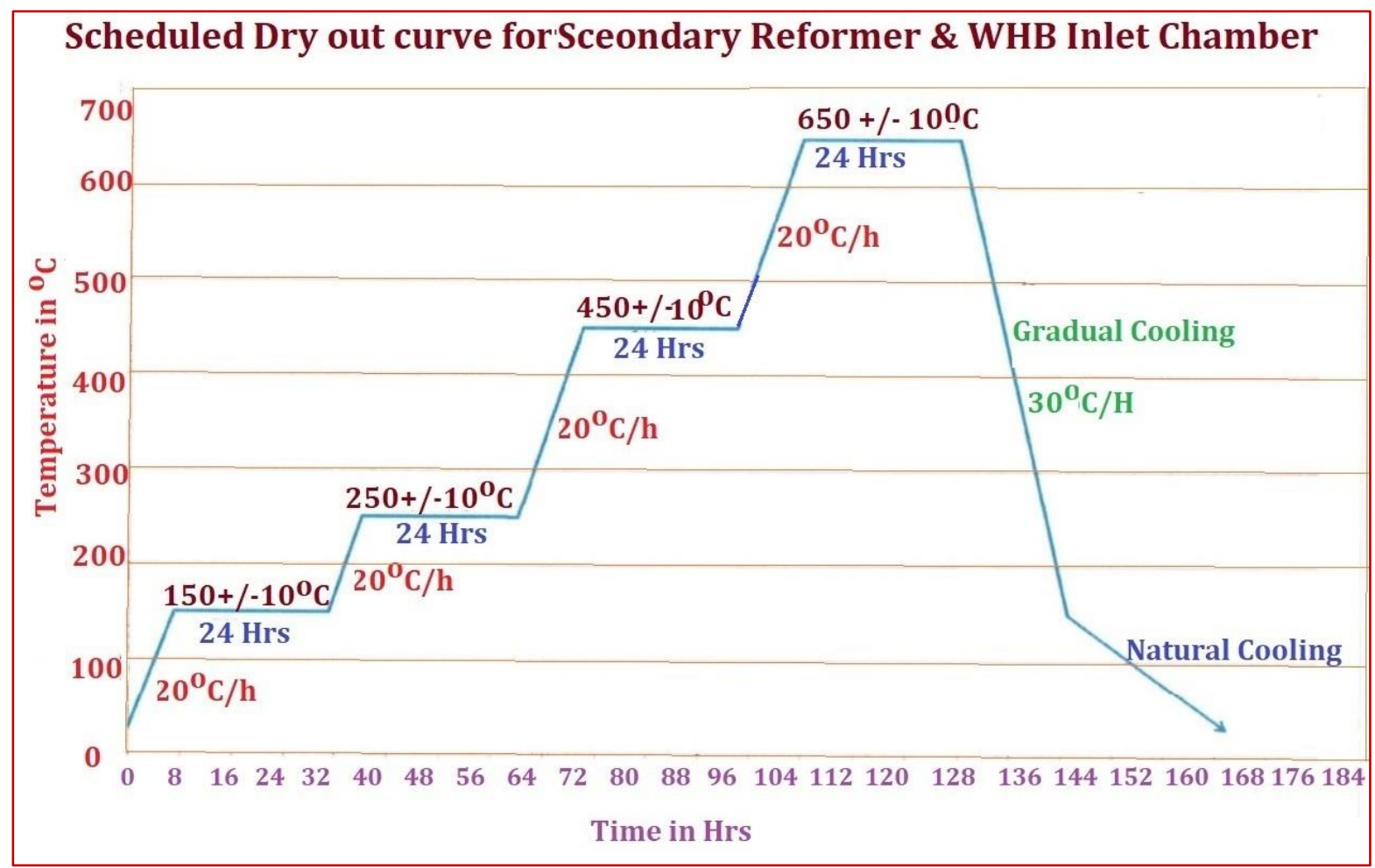

Fig-9(Scheduled Programme for secondary reformer and inlet WHB)

Summary of the Dry out for secondary reformer $\&$ inlet Chamber

Due to weather condition was not good so extra time was taken for dry out operation.

1. Raised the temperature from ambient to $150^{\circ} \mathrm{C}$. @ $15^{\circ} \mathrm{C} / \mathrm{Hr}$. slowly

2. Hold the temperature at $150+/-10^{\circ} \mathrm{C}$ for $36 \mathrm{hrs}$.

3. Raised the temperature to $250^{\circ} \mathrm{C}$ gradually @ $15^{\circ} \mathrm{C} / \mathrm{Hr}$.

4. Hold the temperature $250^{\circ} \mathrm{C}+/-10^{\circ} \mathrm{C}$ for $24 \mathrm{hrs}$.

5. Raised the temperature to $450^{\circ} \mathrm{C}$ gradually @ $15^{\circ} \mathrm{C} / \mathrm{Hr}$.

6. Hold the temperature $450^{\circ} \mathrm{C}$ for $24 \mathrm{hrs}$.

7. Raised the temperature $650^{\circ} \mathrm{C}$ gradually @ $15^{\circ} \mathrm{C} / \mathrm{Hr}$.

8. Hold the temperature 650 for $40 \mathrm{hrs}$. (Differ from scheduled due to rain).

9. Start gradual cooling@ $25^{\circ} \mathrm{C} / \mathrm{hr}$.to ambient temperature.

Tube sheet Temperature after blind at $650^{\circ} \mathrm{C}$

Inside Temperature- $650^{\circ} \mathrm{C}$

Outside Temperature- $35^{\circ} \mathrm{C}$

Heat Transfer Coefficient- $1000 \mathrm{wm}^{2} \mathrm{~K}$ (Inside), $9.015 \mathrm{wm}^{2} \mathrm{~K}$ (outside)

Lining Characteristics-

Heat Loss-268.2 $\mathrm{wm}^{2} \mathrm{~K}$

Heat Storage- $197 \mathrm{MJ} / \mathrm{m}^{2}$

Weight $-899.8 \mathrm{~kg} / \mathrm{m}^{2}$

Total Thickness-3515 mm $(3100+311+462+230 \mathrm{~mm})$

Wall layers from inside to outside)

\begin{tabular}{|c|c|c|c|c|c|c|c|}
\hline \multirow[t]{2}{*}{ Sr.No. } & \multirow[t]{2}{*}{ Material } & Thickness & Density & Classification & Border & Mean & $\mathrm{K}$ mean \\
\hline & & $\mathrm{mm}$ & $\mathrm{Kg} / \mathrm{m}^{3}$ & ${ }^{0} \mathrm{C}$ & ${ }^{0} \mathrm{C}$ & ${ }^{0} \mathrm{C}$ & $\mathrm{w} / \mathrm{mK}$ \\
\hline 1 & Brick L260 GS & 230 & 800 & 1400 & 650 & 556 & 0.3278 \\
\hline 2 & $\begin{array}{l}\text { CF blanket } \\
1260^{\circ} \mathrm{C}\end{array}$ & 50 & 96 & 1260 & 461.8 & 390 & 0.0884 \\
\hline 3 & Didoflo K98-3 & 75 & 3150 & 1800 & 310.6 & 307 & 2.816 \\
\hline 4 & Steel & 30 & 7850 & 400 & 303.4 & 303 & 46.42 \\
\hline 5 & Air Gap-150 & 3100 & 1.225 & & 303.3 & 210 & 3.987 \\
\hline 6 & Steel & 30 & 7850 & 400 & 64.9 & 65 & 53.69 \\
\hline
\end{tabular}

Table-1(Detail of layers) 


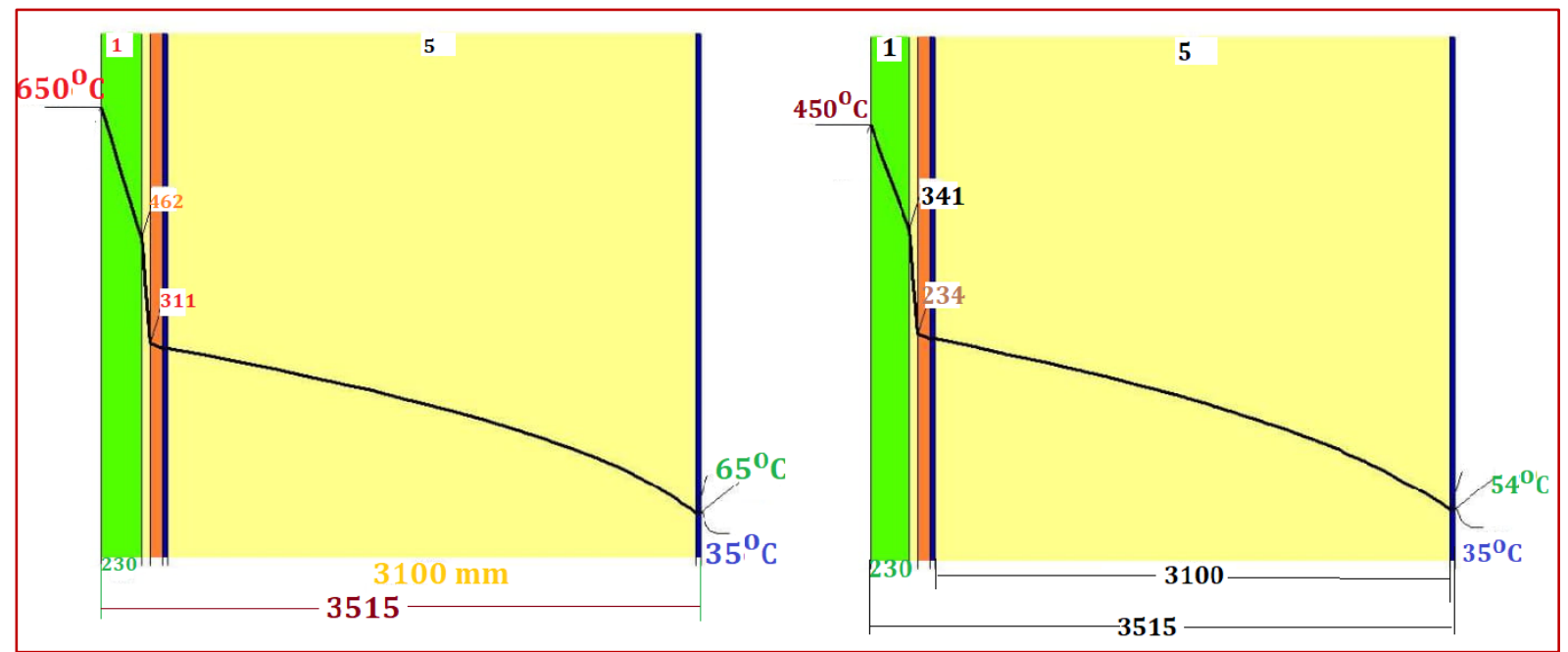

Fig-10(Detail THK of layers \&Temperature distribution on layers)

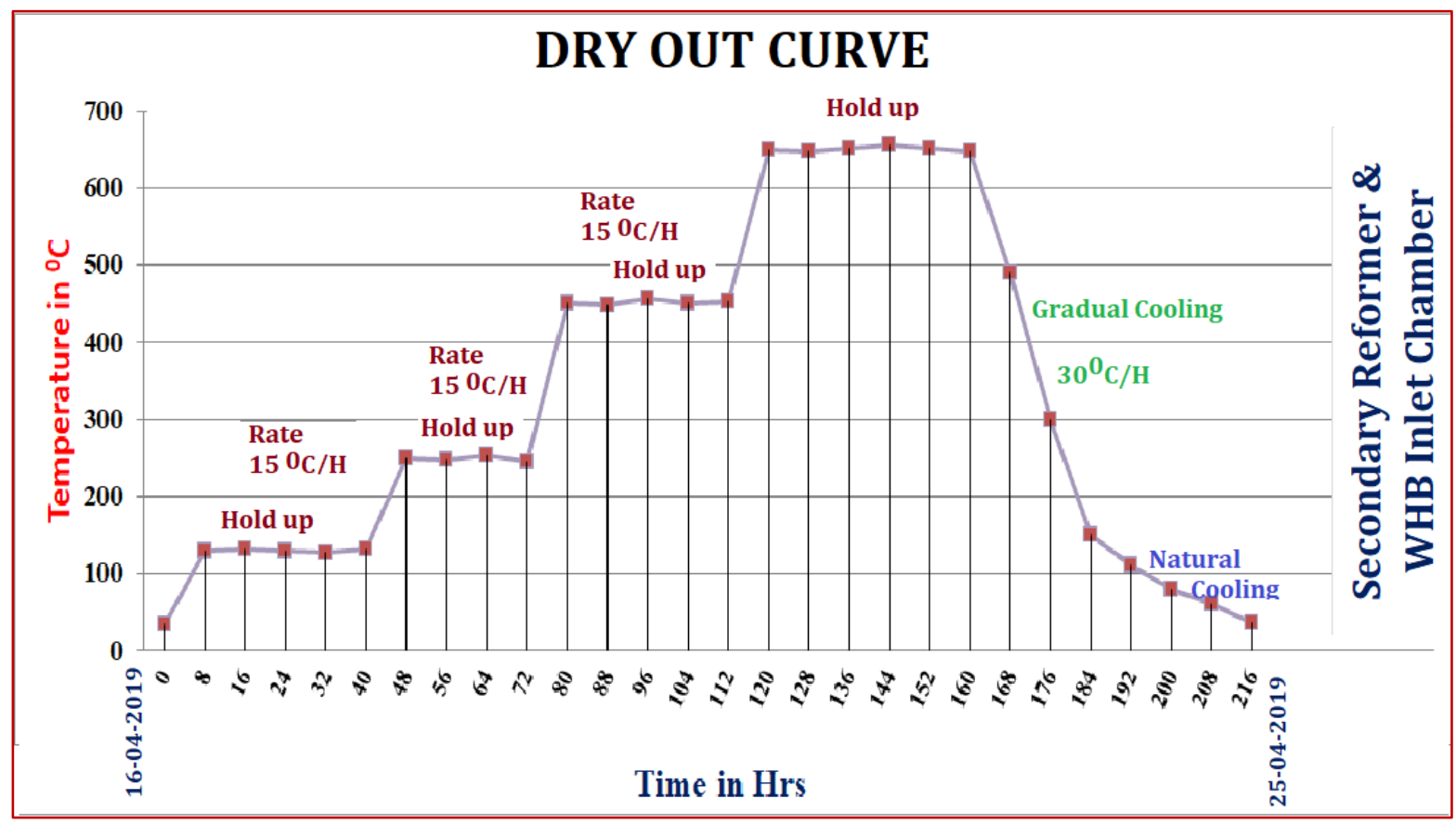

Fig-11(Actual dry out temperature Vs. Time curve)

During the dry out an outside insulation was composed by two layers of places $25 \mathrm{~mm}$ thickness applied in segment to the equipment. The insulation segments was removed once the vessel steel shell temperature exceed $110^{\circ} \mathrm{C}$.The dry out was completed only if at all of the outer steel a temperature of $\geq 110^{\circ} \mathrm{C}$ could be maintained for 12 hrs to ensure proper water removal for refractory lining. Overheating of the vessel steel shell was avoided by all means. The maximum allowable steel temperature was $160^{\circ} \mathrm{C}$.External insulation was removed immediately once the steel temperature exceeds $110^{\circ} \mathrm{C}$.

Summary for Intermediate part of waste heat Boiler.

1. Raised the temperature from ambient to $130^{\circ} \mathrm{C}$.

2. Hold the temperature at $130^{\circ} \mathrm{C}+/-10^{\circ} \mathrm{C}$ for $15 \mathrm{hrs}$.

3. Raised the temperature $250^{\circ} \mathrm{C}$ gradually @ $15^{\circ} \mathrm{C} / \mathrm{hr}$.

4. Hold the temperature $250^{\circ} \mathrm{C}+/-10^{\circ} \mathrm{C}$ for $24 \mathrm{hrs}$.

5. Raised the temperature up to $400^{\circ} \mathrm{C}$ gradually @ $15^{\circ} \mathrm{C} / \mathrm{hr}$.

6. Hold the temperature at $400^{\circ} \mathrm{C}$ for $32 \mathrm{hrs}$.(differ from scheduled due to bad weather)

7. Start gradual cooling @ $25^{\circ} \mathrm{C} / \mathrm{hr}$ to ambient temperature.

After completion of dryout refractory inspection was carried out and found ok. 


\section{Scheduled Dry out curve for Intermediate Chamber of Waste Heat Boiler}

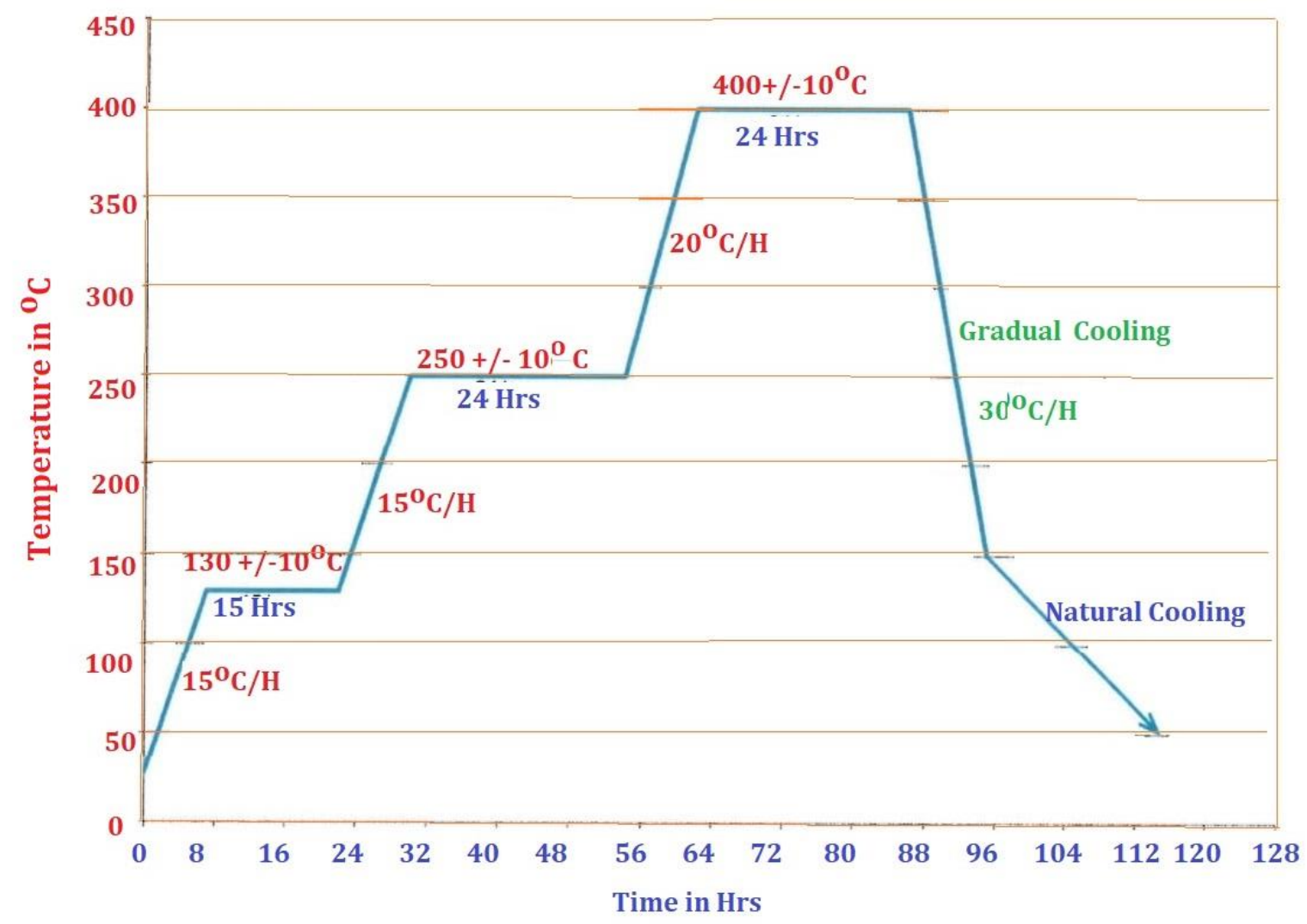

Fig-11(Scheduled programme of intermediate chamber of WHB)

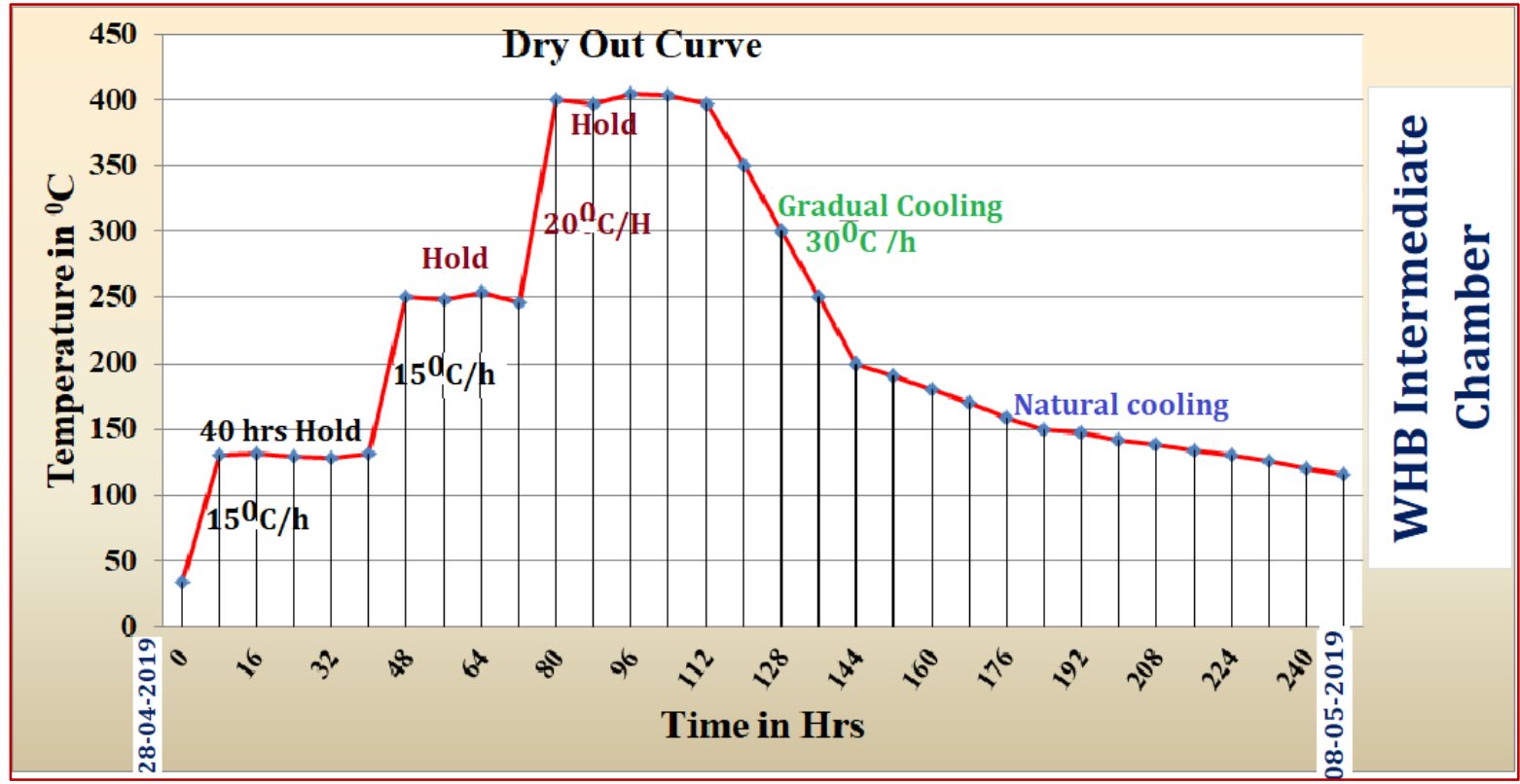

Fig-12(Actual temperature Vs Time for WHB intermediate portion) 


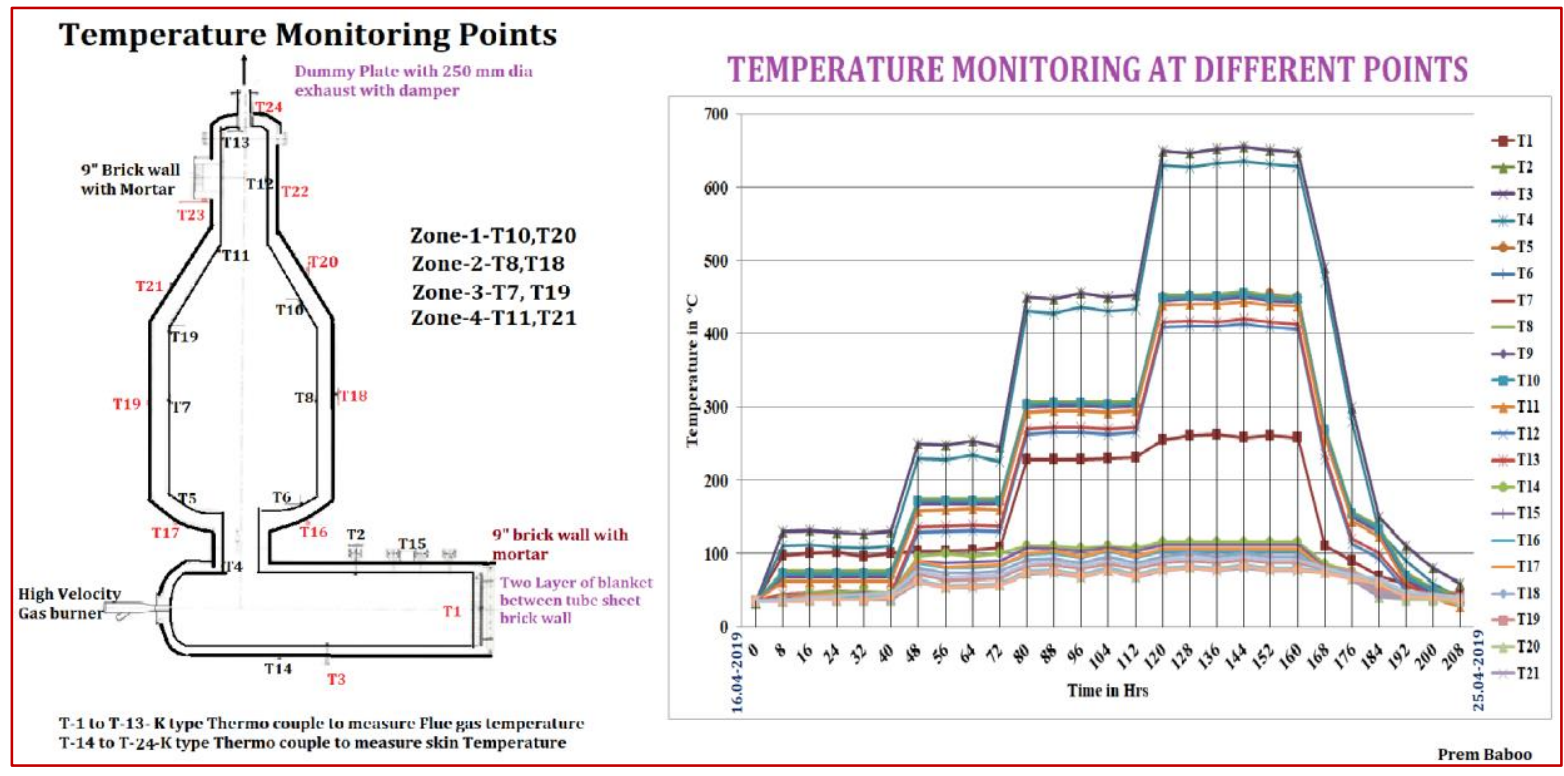

Fig-13(Different temperature thermocouple location \& Temp Vs. Time)

\section{OBSERVATION AFTER DRY OUT OPERATION-}

Secondary reformer and waste heat boiler tube sheet checked after removal of bricks wall found ok and Hammer test was ok, small yellowish marks observed on tube side casting. No cracks were observed. At one point on top side of discharge end some sound difference (hollow sound) was noticed, overall report of dry out found ok and these test was done by NDT department.

\section{CONCLUSION}

The heating profile inside the castable is therefore clearly related to the dewatering stages, providing an indirect assessment of the maximum steam pressure buildup developed inside the pores, thus guiding the choice of heating schedules that minimize the risk of explosive spalling. There are a number of factors that can affect the lifespan of cast refractory lining dryout operation, heating rate as well cooling rate, a successful operation requires a fine balance of many factors, as well as an interdisciplinary attitude by all parties involved in the drying out operation, supply, installation, and end use. A complex combination of knowledge and skills acquired through education and training by all parties involved is required in order to ensure that a cast refractory drying out reaches its full design lifespan. In addition, stringent quality control procedures and checks during every stage of the refractory drying out, from conception to maintenance, should be implemented to ensure a maximum-life refractory lining installation. Placement of thermocouples (No. and location) is also very important to monitor the dry out cycle. Inspection after the dry out for any cracks or bulging etc was carried out. Depending upon the defects repair strategy could be evolved. It must be remembered that the refractory lining is installed inside the pressure vessels as well as fired heaters.

Legends-

Ppb-parts per billion, G.Cal-Giga calories, ppb-parts per billion, WHB-waste Heat Boiler, CNG-Compressed natural Gas. HV-High velocity. NDT-Non- destructive Test.

\section{REFERENCES}

[1] Characterisation of thermo-mechanical behaviour of high Alumna refractories for secondary reformer application by Ranjan Dey, Ravikumar N., Eswaran V. T., Sudip Kumar Paul, Rajagopalan R.Carborundum Universal Limited, Chennai, India.

[2] Drying stages during the heating of high Alumina ultra-low cement refractory castable by Murilo D. M. Innocentini, Fa'bio A. Cardoso, Mario M. Akyioshi, and Victor C. Pandolfelli J.M. ceramics Soc 86(7) 114648-48(2003)

[3] Refractory Dryout by Irbin C. Cobane,Hotwork, April 23,2002

[4] Important Considerations for Refractory Dryouts, Startups \& Shutdowns by Jim Jenkins, Shell International Exploration and Production, Houston, Texas, 2011 Sulfur Recovery Symposium in Vail, CO. - Brimstone STS Limited - September 13-16, 2011.

[5] Magnesia refractory dryout-managing the risk of hydration by J.D. Steenkamp, H. Kotzé, J.G. Meyer, and J. Barnard* The Journal of The Southern African Institute of Mining and Metallurgy Volume-111, JUNE 2011423 